International Journal of Engineering \& Technology, $7(3.2)(2018) 649-652$
International Journal of Engineering \& Technology
SPC
Website: www.sciencepubco.com/index.php/IJET
Research paper

\title{
Preservation of the Historical Architectural Environment in a Modern City
}

\author{
Volodymyr A. Nikolaenko ${ }^{1}$, Volodymyr V. Nikolaenko ${ }^{2 *}$, Oleksandr Zubrichev $^{3}$ \\ ${ }^{1}$ Poltava National Technical Yuri Kondratyuk University, Ukraine \\ ${ }^{2}$ Poltava National Technical Yuri Kondratyuk University, Ukraine \\ ${ }^{3}$ Poltava National Technical Yuri Kondratyuk University, Ukraine \\ *Corresponding Author E-Mail: Dastam@I.Ua
}

\begin{abstract}
In the article the problem of preservation of monuments of architecture in the modern city is considered. Today, this is one of the main tasks of urban development, which is associated with a change in the filling of the architectural environment of the historical centers of the modern city. The experience in this area is generalized in order to reveal new principles that allow testing on the real material the interaction of structures of different epochs for understanding their reconstruction, preservation and protection. In the field of protection of architectural monuments, there is no necessary legal support, as well as guarantees of investments for maintaining and preserving the historical environment. The research was carried out, first of all, on examples of historical architectural objects of the city of Poltava, where, along with architectural monuments, construction of new buildings takes place, which in most cases do not correspond to the stylistic features of historical buildings and distort the urban historical environment, not taking into account the traditions and practice of building previous centuries.
\end{abstract}

Keywords: architecture, architectural monuments, modern city, preservation, reconstruction.

\section{Introduction}

Architects have always considered the city as an integral cityplanning system, in which socio-economic, environmental and architectural-planning problems form a single whole.

According to statistics, in Ukraine, as of 2003, there were 16237 architectural monuments, including 3541 monuments belonging to the category of national significance, and 401 cities and towns received the status of historical.

The approval of Ukraine as an independent state is inextricably linked with the cultivation of a national cultural heritage. This is one of the prerequisites for our path future.

The Constitution of Ukraine, the current legislation states that all historical and cultural monuments located on the territory of Ukraine are protected by the State.

Ukraine, as a member of the Convention "On the Protection of the World Cultural and Natural Heritage," pledged to provide protection, preservation in a proper condition of the cultural heritage located on its territory.

Today more than 150 thousand immovable monuments of history and culture are taken under state protection, including 15,600 architectural monuments and city-planning, from which the St. Sophia Cathedral with the ensemble of buildings and the KyivPechersk Lavra, as well as the historical center of Lviv are included UNESCO World Heritage List, and 3,541 objects belong to the category of monuments of national significance.

The topic of the study is related to a number of international memorial and legal documents, including: the Venetian Charter of 1964, the Paris Convention for the Protection of the World and Natural Heritage of 1972, the Granada Convention for the Protection of the Architectural Heritage of Europe of 1985, the Washing- ton International Charter for the Protection of Historical cities of 1987, national programs for the preservation of historical and cultural heritage.

\section{Main Body}

In the development of modern Ukrainian architecture the problem of correlation between architectural monuments and modern city is increasingly highlighted and becomes more relevant. The role of architectural monuments in urban planning is constantly changing. Especially the new wave of restoration and reconstruction of destroyed and damaged cathedrals, temples, churches has spread, which of course in time of raising the spirituality of Ukrainian society, has its positive qualities. Along with this there is the construction of new structures of sacral architecture, the inclusion of which in the urban ensemble, in most cases, does not based on traditions which has already worked out and in general, they significantly different from the practice of previous centuries. Along with this there is the construction of new structures of sacral architecture, the inclusion of which in the urban ensemble, in most cases, does not based on traditions which has already worked out and in general, they significantly different from the practice of previous centuries.

On the one hand, scientific and technological progress greatly enhances the possibilities of intensive use of natural resources necessary for the further development, maintenance and satisfaction of material and spiritual needs of society, and on the other hand, it often complicates the relationship between man and the surrounding environment, makes significant changes to the ecological systems that have a close connection with city-planning systems. 
Over time, the problem of the existence or maintenance of architectural monuments in a modern city becomes one of the most serious and complicated tasks of modern urban development. First of all, it is connected with the change in the filling of the architectural environment of the historical centers of the modern city, its saturation with the objects of advertising, visual information, which more and more destroys the relationship between architectural monuments and modern city.

In recent years the first steps in this direction has already made in the practice of Ukrainian literature, which are partly false, partly compromise, but they allow to check the basic principles of interaction between buildings of different eras. The generalization of experience in this field, the discovery of new principles is one of the most important tasks of modern urban planning, and it is also necessary, because every mistake embodied in life, begins to serve as an example and justification for further projects.

The problem of finding expressiveness, imagery and continuity at all stages of the development of architecture remains almost the most important. The work of the architect is particularly successful when it is followed by a bright individual personality of the author who can not only harmoniously combine architectural elements into the perfect composition, creating perfect plastic of shapes, but also put it on the solid basis of tradition. The degree and manner of such a connection, obviously, is determined in each case in its own way, but the presence of the visible or subconscious gives the outside observer understanding of the logic of the new, and therefore the modern one.

Cultural heritage is a collection of inherited humanity from previous generations of objects of material and spiritual culture. The object of the cultural heritage is a prominent place, a building (work of art), a complex (ensemble), their parts, moving objects associated with them, as well as territories or water objects, other natural, natural - anthropogenic or person-created objects, regardless of the state of preservation, which has brought to our time the value of archaeological, esthetic, ethnological, historical, architectural, scientific or artistic view and retained its authenticity. If the object of cultural heritage is entered into the State Register of immovable monuments of Ukraine, then it acquires the status of a cultural heritage monument.

Therefore, understanding the existing practice of Ukrainian architecture in terms of attitude to architectural monuments and the uncompromising evaluation of one or another technique is not only a theoretical but also a practical necessity.

It should be emphasized that these problems become more complex every year. The number of architectural monuments is expanding more and more, the cities are subject to radical changes. Buildings, which until recently could be attributed to buildings of modern architecture, they transformed into architectural monuments over time. Now more and more people talk about the need to preserve as architectural monuments buildings 50-60s years. This diversity of different epoch architectural monuments suggests the difficulty of their integration into a single architectural ensemble of the modern city. If we add to this the "relationship" with modern architecture, it will become clear how complicated the task of urban planners.

The contradiction between the historical and modern architecture can not be avoided, they can only be overcome by a concrete analysis of the urban development situation in each particular case. But until recently these contradictions were not trying to solve.

If we turn to history, then we see the compositional combination of buildings, which are different in construction times, have repeatedly created a complete holistic ensemble, but with each subsequent decade, the large divergence between buildings of different construction periods is increasingly deepening.

During the last decade, the problem of the correlation of modern architecture and the legacy of the past, at first glance, did not become so acutely. The tendency to restoration of historical architectural forms led to the fact that "illusory" stylistic closeness united buildings of different epochs. But the desire to imitation of histor- ical forms does not always serve as a guarantee of preservation of the monuments.

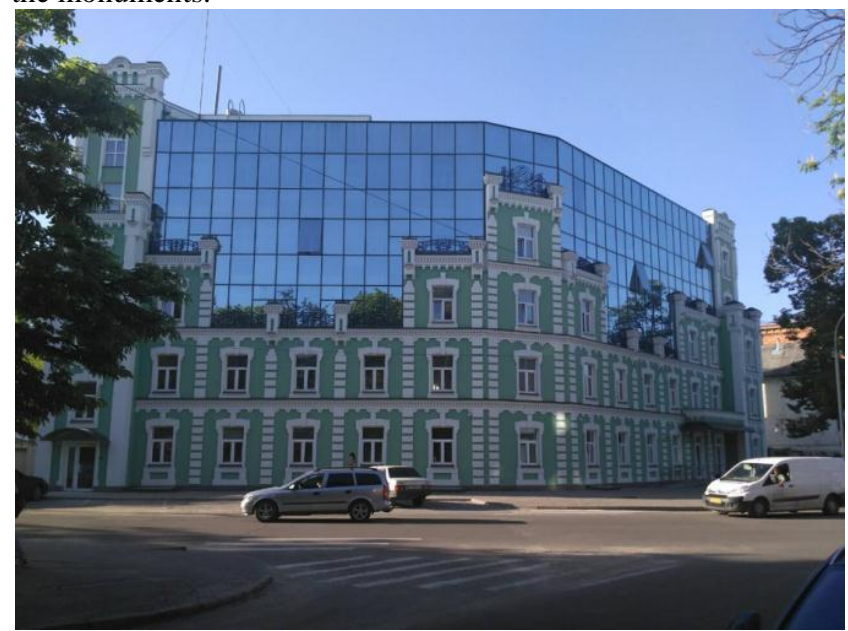

Fig. 1: Modern building on the Gagarin Street, Poltava

These tendencies were inherited when the architectural features of 50-60s began to form. We do not have to analyze carefully how in those days the question was solved to the conservation of monuments. We emphasize only that despite calls for the preservation of the value which was created in the past. In these years many buildings were destroyed, which embodied the best features of national architecture. Destruction of architectural monuments was not always dictated by the objective needs of the development of a modern city, and most of all by the requirements of declarative acts.

The fact that architectural monuments began to rebuild during the years of statehood in Ukraine, indicates the great importance that has been given to them as symbols of the greatness of national culture.

The revival of architectural monuments became perceived inseparable from the resurgence of native land. Works on the reconstruction and restoration of architectural monuments have gained considerable development, which, in turn, were affected the general condition of restoration science. Now work is underway to clarify the scientific principles and methods of restoration.

Testing methods and techniques of restoration is a quite difficult task. The diversity of architectural monuments and a large number of different city-planning situations dictate its unique solution in each individual case and, therefore, to find a ready-made answer to all the difficult issues of restoration is quite problematic. At the same time, the level of development of the methodology of restoration and pre-researches, in general, has not yet received confirmation in urban planning practice.

If you do not take into account some differences, then the techniques which offered now are quite similar. These are, first of all, historical and documentary studies of written, iconographic and cartographic materials, through which a more complete picture of the development of the city's architectural and planning structure is restored, and on this basis, the retrospective reconstruction of its historical architectural structure and historical and topographical reference plan consists which is specified by field examination.

During the process of field research, retrospective reconstruction helps to restore the compositional and spatial patterns of building a city with a historical past: visual bonds, zones of vision and zones of composite influence of dominants, which, in combination with the historical topographic plan, makes it possible to draw up a scheme of the historical part of the city.

Along with this, researches are also needed that involves analyzing the processes of formation of the city's historical environment - stratifications, additions and changes, and not only historical ones, but also in the aspect of those economic and social components which these changes have identified. On this basis, we can conclude that the constructive preservation of the historical nucleus can only be achieved on the basis of the renewal of the signs 
and values of the ancient city, rather than through simple scenery in the form of functional rebuilding.

Thus, the historical core should occupy a special place in the functional structure of the city. The historical core can carry the functions of the city center only in those cases where its territory occupies a significant part of the entire city territory, and the development of the city is negligible or absent altogether. At the same time, historical building has always been seen in the context of two aspects: by the degree of reconstruction and, if possible, use for other functions. In the first case, the following principles of possible reconstruction are used: restoration with absolute limitations; improvement (restoration with partial rebuilding) - renovation of the interior while maintaining functional and structural characteristics and reconstruction with several constraints; demolition and rebuilding or demolition with possible rebuilding elsewhere. Accordingly, in the second case, the bulk-spatial characteristics of historical development should serve as the basis for the typology of the possible use of historical buildings.

Speaking about the role played by architectural monuments in the modern city, we can not avoid the question of their protection. But this is a separate complex subject, although it is closely related to the problem in question. The reconstruction of the old areas of historical cities, of course, always puts the issue of protection along with their restoration for architects. It is very unfortunate that in some cases these issues are resolved unambiguously. Naturally, the preservation of the architectural monument and the inclusion of it in a new ensemble at a certain stage greatly complicate the task of the architect. At first glance, it seems less difficult to create a new complex than to search for special artistic techniques for association with buildings of another era. In fact, the exclusion of historical buildings, as a rule, impoverishes the ensemble, especially since modern architecture still does not have enough expressive means to generally replace the historical building.

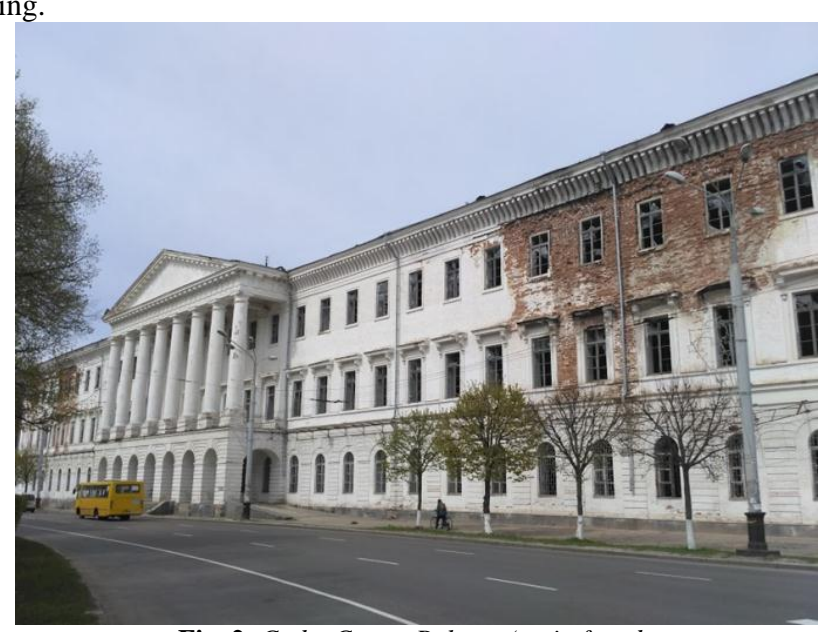

Fig. 2: Cadet Corps, Poltava (main façade

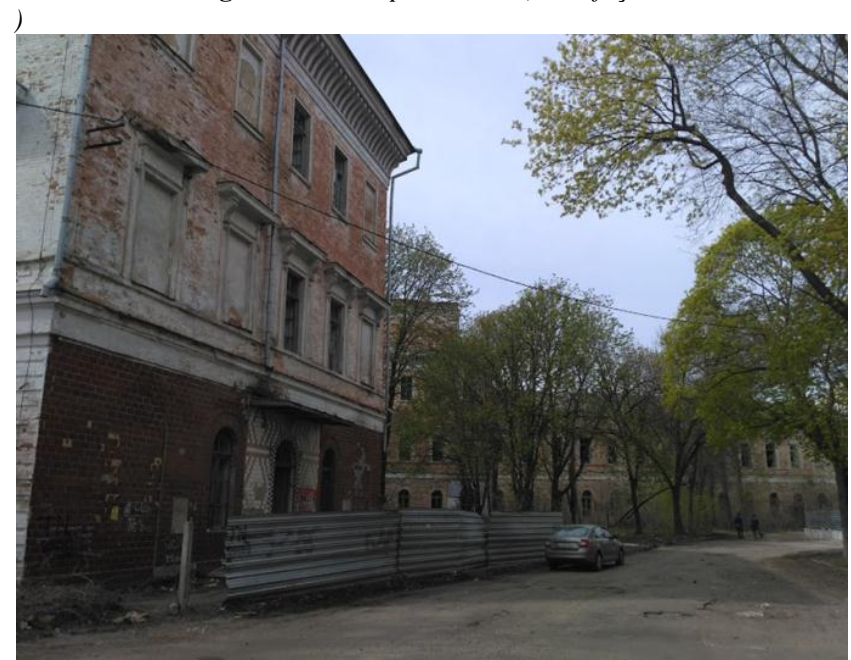

Fig. 3: Cadet Corps, Poltava (side facade)
Different methods of communication only begin to be more consistent in attempts to work out reconstruction methods in modern conditions. This is compounded by the fact that the diversity of monuments and the plurality of different city-planning situations dictate in each individual case its unique solution and find a readymade answer to all complex issues is practically impossible.

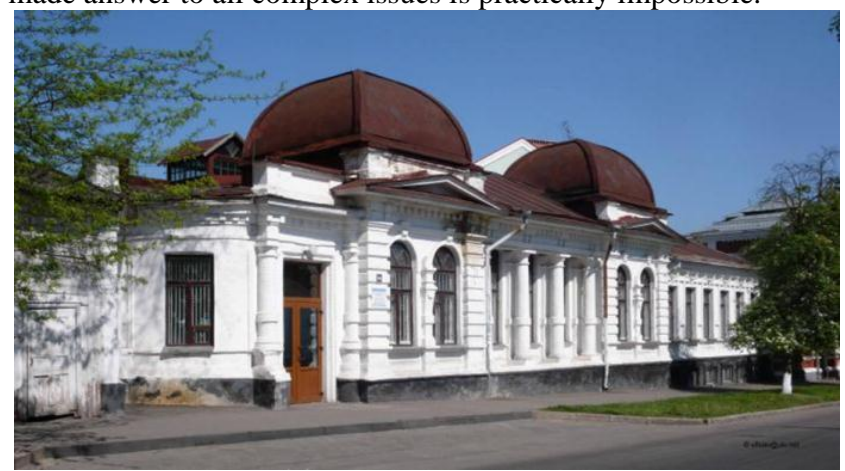

Fig. 4: Music classes of Theophany Bazylevych (photo from archive)[6]

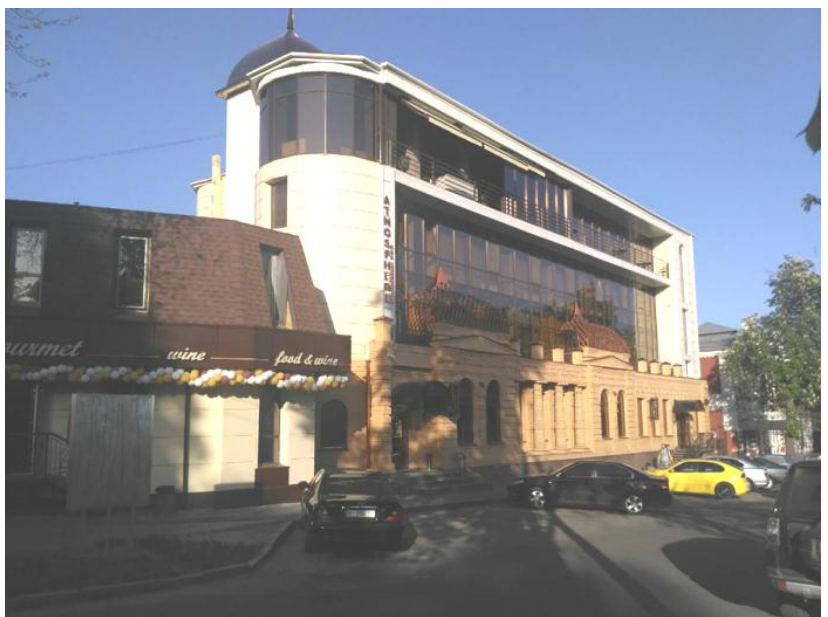

Fig. 5: Hotel and restaurant complex (on the spot of music classes The ophany Bazylevych)

One can only assure that the abandonment of traditional forms in modern Ukrainian architecture does not place architectural monuments in more difficult conditions than during the Soviet period. Now there are a number of compositional techniques that allow you not to reproduce the direct imitation of the form, to combine old buildings with new ensembles. Great successes in this direction were already achieved in the medieval cities of Western Europe, where the new buildings, while preserving their individuality, master the internal construction of ancient monuments, the dynamics and expressiveness of their volumes.

Ancient architecture can reliably tell the architect when designing new homes, along with architectural monuments and a leading compositional motif, and relevant material and techniques for connecting with the landscape without disturbing, with the contemporary nature of buildings. Therefore, architects often have to turn to the achievements and traditions that shaped the Ukrainian style in architecture and to the use of elements of Ukrainian arts and crafts, especially in the interiors of new buildings.

Such an attitude only begins to emerge in contemporary Ukrainian architecture. However, the changes that have taken place in recent years, suggest that the search for architectural connection with the ancient historical architecture is increasingly becoming a topical issue of contemporary Ukrainian architecture.

Today the most serious problem of the monument protection sphere remains its legal providing, including guarantees of nonstate investments in the maintenance, protection, restoration and use of historical and cultural monuments.

The tasks that remain unresolved are the following:

- Transfer of architectural monuments to private property without proper control over their preservation; 
- Lack of enforcement of laws on ensuring their safety;

- Lack of allocation of necessary funds for restoration and reproduction;

- Compromise solutions of modern functional purpose of architectural monuments.

\section{Conclusions}

The solution of these tasks at the modern European level should be ensured by the Law of Ukraine "On the Protection of the Cultural Heritage", adopted by the Verkhovna Rada of Ukraine on March 16, 2000. This law ensures not only the legal and organizational principles of the protection of monuments, but also creates the economic basis for effective memorial protection and restoration activity. In particular, the law provides for the exclusion from taxation of sums directed at the purpose and used for the protection and restoration of monuments; exemption from taxation and grant of subsidies to non-profit organizations working in the field of protection, restoration and use of historical and cultural heritage. To ensure the protection of the architectural heritage of Ukraine should identify the most valuable attractions for their restoration. The rest of the monuments should be preserved and included in the information database, which should include dimensional drawings, photographic materials, historical references, etc.

To provide the processes of managing the protection of cultural heritage in accordance with Article 3 of the Law of Ukraine "On the Protection of the Cultural Heritage", should be created a system of specially authorized cultural heritage protection bodies: the central executive body in the sphere of cultural heritage protection, bodies at regional and district state administrations and bodies of local self-government.

\section{References}

[1] Architectural heritage and restoration / ed. V. Dvoryashin. - M.: Rosrestavratsiya, 2016. - 356 p.

[2] E. Zuevskaya. Anthology of cultural heritage. Music, literature, painting, sculpture, architecture / E Zuevskaya. - M.: Kontent, 2010. - 740 p.

[3] Architectural monuments and urban planning of Ukraine: Directory of the State Register of National and Cultural Heritage. - Illustrative block. - K. Technics, 2000. - 664 p.

[4] Essays on the history of architecture of the Ukrainian SSR (preOctober period). - K .: State Publishing House of Literature on the Construction and Architecture of the USSR, 1957 - 557 p.

[5] Electronic source http://zakon2.rada.gov.ua/laws/show/1805-14

[6] Electronic source http://wikimapia.org/24607797/ 